\title{
Gender Diversity in Computing and Immersive Games for Computer Programming Education: A Review
}

\author{
Chyanna Wee ${ }^{1}$, Kian Meng Yap ${ }^{2}$ \\ Department of Computing and Information Systems \\ Sunway University, Bandar Sunway, Malaysia
}

\begin{abstract}
This paper provides a review of the current state of the gender gap in computer science and highlights how immersive games can mitigate this issue. Game-based learning (GBL) applications have been shown to successfully incite motivation in students and increase learning efficiency in both formal and non-formal educational settings. With the rise of GBL, researchers have also used virtual reality to provide pupils with a more immersive learning experience. Both GBL and virtual reality techniques are also used for computer programming education. However, there is a paucity of applications that utilize these techniques to incite interest in computer science from a female perspective. This is a cause for concern as immersive games have been proven to be capable of inciting affective motivation and fostering positive attitudes towards specific subjects. Hence, this review summarises the benefits and limitations of GBL and virtual reality; how males and females respond to certain game elements; and suggestions to aid in the development of immersive games to increase female participation in the field of computer science.
\end{abstract}

Keywords-Computer science education; game-based learning; gender; virtual reality

\section{INTRODUCTION}

The projected number of degrees awarded to females was estimated to increase from 39 percent in 1966 to 61 percent in 2019 [1]. Despite the increasing number of degrees awarded to females, only about 35 percent of them are enrolled in Science, Technology, Engineering, and Mathematics (STEM) courses [2]. To make matters worse, the dropout rate for female students is 23 percent higher than for males in STEM courses [3]. The gender gap is most prominent in the field of computer science, where estimates of the ratio of male to female enrolment at tertiary level are approximately 70:30 as of 2019 [4]. This may be attributed to the gender gap in computer science advance placements (AP) test-takers where there were 52,574 males to just 17,111 females in 2019 [5]. Collectively, all this data means that females make deliberate decisions when it comes to not pursuing a career in the computer science field. Although there are several contributing reasons for this, the main factor stems from stereotypical representations of STEM-related fields that implicitly deter females and give them an incorrect perception of what the field is made of [6].

Due to low female enrolment rates in computer science, there is a lack of diversity in the computing workforce. According to data provided by the United States Department of
Labour's Bureau of Labour Statistics (BLS), computer-related jobs are projected to rise by 12.5 per cent from 2014 to 2024 [7]. However, there is still a substantial difference between the number of female employees and the number of male employees in computing professions, with approximately 1,226,000 females compared to $3,578,000$ males [8]. This is also prevalent in the field of academia, where only 15 per cent of professorial computing positions are held by females [8]. Ultimately, this implies that the consequences of low female enrolment rates in computing courses reflect upon the workforce. This is a cause for concern as diversity is crucial to stimulate and trigger innovative solutions to problems in the field.

\section{RELATED WORKS}

In recent years, the game-based learning (GBL) technique is widely used in educational contexts to foster knowledge acquisition, skill acquisition, and engagement in students [9]. To further enhance student participation in the learning process, GBL is also frequently combined with virtual reality and augmented reality. Previous reviews ( [10], [11], [12] ) have covered the benefits of the use of games for programming education. There have also been reviews ( [13], [14]) that highlighted the use of virtual reality in education. More recently, there are also reviews ( [15], [16] ) that discussed the prevalent gender gap in computer science and virtual realitybased research. However, there is a relative paucity of reviews that explored the possibility of utilizing immersive games to increase female participation in the field of computer science.

Therefore, this review aims to foster more research in the development of immersive learning applications to reduce gender gaps in computing. Fig. 1 provides an overview of the topics discussed in this review, starting with why diversity is important in computing and factors that influence female participation in computing. Other major topics can be found in the "Results" section in this review where GBL and virtual reality are explored concerning their application in education and computer programming education to determine if the utilization of these techniques may aid in increasing female participation in the field of computer science. Furthermore, an overview of how males and females perceive game elements are also discussed to further aid in promoting the development of more female-centric immersive games on computing education. 


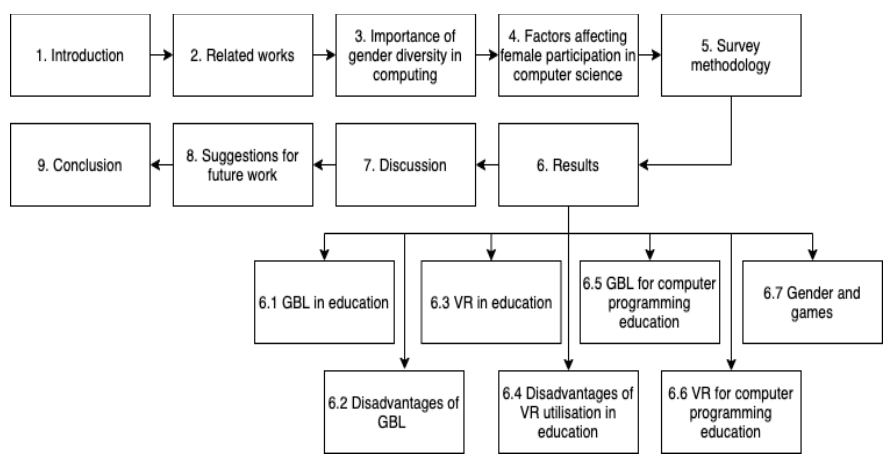

Fig. 1. Overview of the Review Paper.

\section{IMPORTANCE OF GENDER DIVERSITY IN COMPUTING}

With technological advancements in recent years, more jobs in the field of computing are expected. With 598,700 job openings annually from 2018 to 2028, compared to 290,200 jobs for non-computing STEM subjects, the demand for computing graduates has increased and will continue to grow for several years to come [17]. Since this is the case, the enrolment rates for computing courses have also increased by 5.4 percent in 2019 since the previous year [18]. Even so, just 27 percent of females are working in computer-related careers [19]. The gap is more significant in academia, where it is estimated that it would take about 118 years to close the gender gap between authorships and publications related to computer science [20]. This is a cause for concern because diversity will bring different perspectives to the table in terms of understanding and designing solutions for a wide variety of individuals. Take car crash dummies, for example, that are modelled based on a man's body. According to a study by the University of Virginia [21], females have a 47 percent greater chance of facing serious injuries compared to males due to the inaccurate representation of the female body through the dummies. This issue persists in technology where females are more likely to suffer from virtual reality headset-induced motion sickness at 77 percent compared to 33 percent for males [22]. The authors conclude that this is due to the difference in physiological structure of both genders and suggest that manufacturers address aspects of design that are related to one's ability to stabilize their bodies. Ultimately, if these issues continue to persist, the accessibility of new and upcoming technology will only be limited to only part of the population, further perpetuating the already wide gender gap in the field of computer science.

\section{FActors AfFecting Female PARTiCipation in COMPUTER SCIENCE}

Throughout history, the field of computer science has been inherently dominated by males. This is largely due to traditional perceptions of how certain genders are deemed more "suitable" for the pursuit of certain fields. For example, the fields designed to be better suited for females include nursing, teaching, and homemaking. Undoubtedly, this propels them to pursue the previously mentioned careers as parental approval directly influences one's career choices [23]. This, in turn, increases the gender gap and further decreases the sense of belonging of female students in the field of computer science. Because the sense of belonging is a strong motivator for the interest of female students in the field of computer science, this creates a never-ending cycle [24]. The lack of female representation also accelerates the lack of interest in females to pursue computer science. In a study conducted by Hussain et al, female role models can help remove the negative consensus related to computer science [25].

Furthermore, how computer science classes are conducted can also be unappealing to females. In a study conducted by Giannakos et al, poor teaching, excessive workload, and boring classes also contributed to high dropout rates [26]. Syllabi that include real-world problems instead of abstract ones are crucial in making the class seem more interesting [27]. This can be achieved by addressing relevant topics of interest to females, such as developing applications, that may help people or animals. Other than that, grouping strategies that foster cooperation and discussion can also be effective [28]. This is because females prefer to work in groups and have a lower level of confidence in themselves and their abilities [29]. As for their male counterparts who have a higher level of confidence in their skills, they often prefer to work on their own [29]. However, because there are often more males than females in computer classes, collaboration can also be an issue. In combination with stereotypical perceptions, females may feel shunned and are therefore unable to participate in class [30]. According to Hoegh and Moskal, the most likely step in eliminating the declining numbers in computer science enrolment is to understand the students' attitude to the field [31]. Despite having equal access to computers as their counterparts, females generally have a negative attitude towards computing and are found to be less concerned about anything that involves computing [32]. Consequently, Jo Tondeur et al found that females also have a less positive attitude compared to males towards computers in general [33]. The societal perceptions of computing-related careers can also increase cynicism in females. For example, students are made to believe that those with computing careers have to face computers all day long and that it will make them seem unsocial [34]. This problem stems mainly from a lack of understanding on what professionals do in different fields of computing. Researchers at Carnegie Mellon University found that many students picture computer science students to be intense hackers, which can also be unappealing to those that have aspirations to do more than technical work [35]. In response to this, changes were introduced in the curriculum to emphasize that there is more to computer science than just being a "hacker". Since then, from just seven female students from a total of 95 students in 1995, it was reported that 105 female students were enrolled into the computer science course from a total of 211 students in 2018 [36].

Lastly, the lack of exposure at an early age also contributes to the gender gap issue. Most computer games and early educational software have been developed and designed predominantly with boys in mind [37]. This, in turn, could explain why males today are more familiar with computers and seem to have a head start in classes. This, coupled with the stereotyping that has been mentioned, may intimidate females and lead to early termination of the computer science class or course in higher levels of education. This can also cause a decrease in the confidence of one's technical skills and 
abilities, which in turn, further inhibits female participation in the field of computer science. However, in a study conducted by Chen, although males had more motivation than females due to prior experience, males were outperformed during the performance evaluation [38]. This means that given the right instructional simulations, even learners without computing experience can outperform those with computing experience effectively. Consequently, according to LaBouliere et al, females may also face a dip in confidence if they are unable to observe their finished product [39]. Hence, to address these concerns, immersive games can be developed to foster interest as well as motivation in computing.

\section{Survey Methodology}

Now as we understand the importance of diversity in computing and the factors that affect female participation in computing, the aim of this review which is "to foster more research in the development of immersive learning applications to reduce gender gaps in computing” becomes more important. To support the aim of this review, the following research questions were constructed.

RQ1: What are the benefits of GBL and VR on computing education and how can this reduce the gender gap in computing?

RQ2: What are proposed game elements that can be employed in immersive learning applications to reduce the gender gap in computing?

To answer the research questions posed above, this review will be conducted systematically according to the steps as detailed in sections IV A to C.

\section{A. Definition of Keywords}

To determine how GBL and VR can promote female participation (RQ1), keywords and search terms such as "Game-based learning AND Education" and "Virtual reality AND Education" were first used to first identify how immersive techniques affect learning in general. Keywords such as "Game-based learning AND Computer education" and "Virtual reality AND Computer education" are then used to identify how both GBL and VR affect computing education. Furthermore, to determine elements that should be employed in immersive learning applications in promoting female participation (RQ2), the keyword “Gender AND Games” were used.

\section{B. Literature Sources}

The search for literature is done through Google Scholar to ensure that there are no biases towards certain databases. It is estimated that almost sixty percent of systematic reviews published fail to retrieve ninety-five percent of available and relevant literature [40]. Hence, the use of a search engine such as Google Scholar would ensure the review includes a more comprehensive sample of literature. To ensure that only the most relevant literature is collected, searches were limited to twenty pages deep and were sorted by relevancy.

\section{Inclusion and Exclusion Criteria}

In this review, literature was also analysed through specific inclusion and exclusion criteria as listed below.

Inclusion criteria

- Literature relevant to keywords specified.

- Literature that is written in the English language only.

Exclusion criteria

- Literature that is duplicated.

- Literature with an abstract only.

Moreover, to ensure that the sources were relevant and suitable for this review, literature was also further analysed through the steps detailed below:

- Analysis of title and abstract.

- Analysis of introduction and conclusion.

- Analysis of entire article.

\section{RESULTS}

Fig. 2 below shows the breakdown of the number of studies selected for each research question during each step of the screening process. Articles that were found to have satisfied all the criteria are discussed in the sections below.

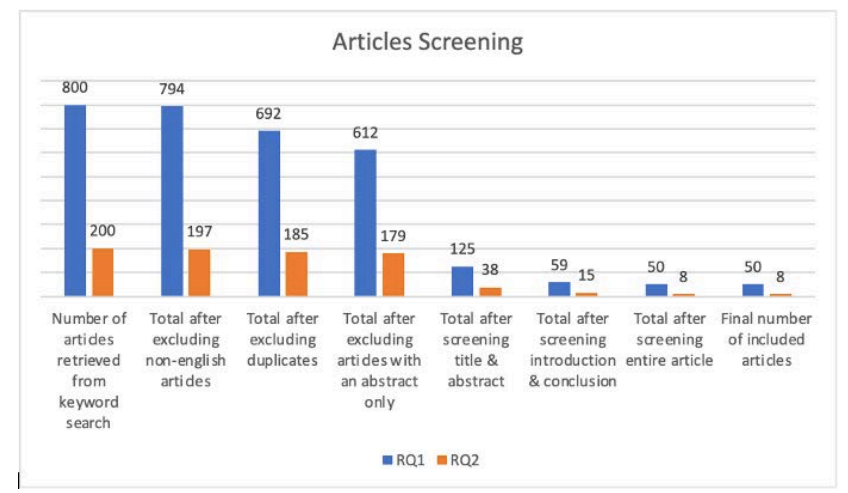

Fig. 2. Article Screening Overview.

\section{A. Game-based Learning in Education}

Contrary to more conventional forms of teaching, those who use educational games or simulations for learning have exhibited positive feedback on knowledge acquisition [41]. Educational games are considered a more organic way of learning because those engaged in gaming from an early age acquire cooperation and thinking skills [42], [43]. For instance, Li et al [44] developed a quiz game resembling "Who wants to be a millionaire" to engage students to learn the Chinese language. The feedback from elementary school students who played the game is mostly positive since students have enjoyed learning through games. Consequently, Yan and Tam [45] also observed the same results after employing a game based on Chinese history. About 81 percent of the participants liked to learn through games and 70 percent conveyed that they gained knowledge from the game. Hence, by using educational games in a classroom environment, students can be more engaged and 
encouraged to actively participate in lessons because GBL focuses on students instead of teachers [46]. This, in turn, will improve students' success from a learning perspective [47], [48], [49], [50].

Apart from engaging students, inciting motivation is also important to ensure that students continue to enquire and participate in the learning process. Cezar et al [51] proposed a Role-Playing Game (RPG) in which participants are required to solve calculus problems to advance through the game. About 83.3 percent of the participants felt motivated to finish the game. Similarly, according to a survey conducted by Yong et al [52] on the feasibility of digital games in mathematics education, 51 percent agreed that mathematics could be more interesting with the use of games. Furthermore, 48 percent agreed that digital games could help with the learning process. Consequently, Lo and Lin [53] proposed a digital board game where the player is allowed to move forward if the mathematical question raised to them is answered correctly. The findings from this study showed a significant difference in attitude before and after the games were played. By incorporating games into the learning process, students will be exposed to interactive learning experiences, increasing interests towards a particular subject matter.

The use of games in the learning process can also be used for the achievement of motor, spatial and cognitive skills. Hogle et al [54] found that those who were trained using a laparoscopic simulator showed an improvement in operative performance and depth perception compared to those who did not use the simulator. Similarly, Stefanidis et al [55] also showed positive results in which participants achieved suture proficiency by using a simulator. In the case of secondary tasks, longer training times are needed to achieve higher proficiency. Furthermore, research done by Green and Bavelier [56] has shown that frequent gamers are more proficient when it comes to tracking simultaneously two more items than those who often don't play. This is also seen in another experiment conducted by Feng et al [57], where the results have shown that when female players were exposed to an action game, both spatial and attentional skills were increased. Barlett et al [58] found that cognitive skills such as memory and auditory perception can also be improved despite playing for a short time only. This fact is supported by Piaget [59] who states that play is integral and evolves with the different stages of cognitive development.

\section{B. Disadvantages of Game-based Learning}

The advantages of GBL, however, depend very much on the design of the game itself [60]. The game must be designed in such a way as to force the player to achieve learning objectives while not being bogged down by the objectives of the game itself. Simply put, this is a contradiction that is difficult to overcome, considering that games are played only for fun, while GBL requires the players to accomplish external goals that are not "fun" [61]. Another limitation to GBL is that players can get bogged down with the idea of the game itself that they cannot think about what they've learnt [62]. For example, students may tend to focus on how their scores compare to that of their classmates rather than the learning objectives that are set for them to achieve. Other than that, GBL applications are usually infused with narratives to engage users. However, this can lead to confusion on the part of the user, as it is often difficult to distinguish between fiction and non-fiction. This phenomenon is prevalent in the results of the research conducted by Huizenga et al [63], in which pupils participate in a game to learn the history of medieval Amsterdam. The team incorporates fictitious narratives to further engage the pupils. This resulted in some confusion as to the actual historical facts and fictional elements of the game.

\section{Virtual Reality in Education}

Virtual reality is also prominent in tertiary education, where it is used in a variety of fields. Dinis et al [64] proposed a software program that allows students to design their threedimensional virtual environment. By doing so students would be able to explore and apply what they have built up in civil Engineering situations. Likewise, Kharvari and Hohl [65] used virtual reality methods for reproducing the virtual form of a building for architecture students to study the precedents of a particular structure without the need for a field visit. The fact that virtual reality is capable of replicating how lightning behaves in a room also favours lightning education as proposed by Boyles et al [66]. Students would be able to interact with different lightning scenarios that are unlikely to exist in the real world.

Furthermore, intending to increase the engagement of students in the field of history, Zhang et al [67] suggested the use of the popular building game, "Minecraft" to build exact replicas of historical monuments. With this, students would be able to map the virtual experience to the knowledge they have gained in a traditional classroom setting. Hence, with the ability to directly interact with the virtual environment, students would be more willing to participate in lessons. By the same token, Lugrin et al [68] developed a virtual reality-based museum where visitors can experience interactive exhibitions without the need to travel to the actual museum. Since virtual reality is capable of effectively reproducing real-life scenarios, Caluya and Santos [69] proposed an authoring tool to study clouds for weather reporting purposes. Depending on the behaviour and appearance of the clouds, the participants in this study are exposed to different sky conditions and how these two factors relate to each other.

Moreover, virtual reality technology is widely used in medical training where live biomedical samples are not always available for training purposes. For instance, Seo et al [70] developed a virtual experience focusing on canine skeletal systems in which participants were able to freely observe and assemble the corresponding limbs. Similarly, de Mauro et al [71] proposed a simulated neurosurgical microscope to train and educate brain surgeons. The simulation focuses mainly on surgical procedures, as well as brain tissue-mimicking to help surgeons determine normal and low-grade glioma tissues. Comparably, Rajeswaran et al [72] developed a virtual experience to instruct medical professionals on endotracheal intubation surgery. Dong et al [73] proposed the integration of virtual reality and haptic feedback to simulate the preparation of cryogenic samples. With haptic feedback, biomedical professionals would be able to learn the best way to handle samples, as the equipment involved in Cryo-Electron Microscopy is expensive and delicate. 
In summary, virtual environments can be developed to provide access to inaccessible places and tools for educational purposes. The utilisation of virtual reality in education also makes the learning process more interactive, which can increase student participation.

\section{Disadvantages of Virtual Reality Utilisation in Education}

Despite its advantages, the use of virtual reality in the context of education also has limitations. According to Mathur [74], despite being able to provide access to inaccessible medical resources, specialised virtual reality systems in the medical field are still prohibitively expensive for widespread adoption. To counteract this, low-poly graphics could be used to build an application because they require less processing power and can make the game run smoothly. This is especially essential for virtual reality games developed for education, so as not to deteriorate the learning experience. Furthermore, because virtual reality applications use Head Mounted Device (HMD) conventional input devices, such as mouse and keyboard, are no longer usable and are instead replaced by controllers. This can be seen in a virtual experience designed by Lei Wei et al [75] that uses Microsoft Kinect controllers. The controllers have been reported to be inaccurate and counter-intuitive, which has undermined the experience of the participants. Virtual reality education systems may also not be sufficiently engaging for users to continue to use them. For example, applications developed by Hsiao et al [76] and Hsieh et al [77], who developed a virtual campus for educators to teach online and a virtual museum respectively, reported a lack of engagement from participants.

\section{E. Game-based Learning for Computer Programming Education}

To make programming more engaging and improve learning, GBL is also often integrated into programming lessons. For instance, Mathrani et al [78] employed the "LightBot" game which required participants to control an animated robot to the end of a maze with the use of blocks representing commands that are similar to code. With a total of twenty participants, the consensus regarding the game was positive in which they found the game to be interesting, fun, and ranked the game as effective in instilling programming concepts like conditionals, functions, and recursion. Olsson and Mozelius [79] tested a memory game that involves matching values to particular data types and a syntax error "bombing" game on sixty-five total participants. Results from the study indicated that both games were successful in effectively helping students practice data types and Python syntax. More specifically, a total of forty-nine students found the games helpful for learning.

Wong and Yatim [80] developed a game called "The Odyssey of Phoenix" to aid in the learning of Object-Oriented Programming (OOP) concepts. This is done by mapping game processes to concepts. For example, the concept of inheritance is mapped to the crafting element in the game where resources required by both the main and nose gear can be shared since they both belong to the gear category. To measure the effectiveness of the game, pre and post-tests results were compared and analysed from 214 first-year students. Results from the study showed improvements in terms of learning effectiveness, leading to the conclusion that GBL is a great tool for knowledge acquisition. Papadakis and Kalogiannakis [81] developed a quiz platform based on multiplayer online roleplaying games (MMORPG) where students can complete programming-based quests and challenges. By conducting surveys on thirty participants from a high school in Greece, the study concluded that the participants were engaged and motivated when completing the challenges presented to them. The authors concluded that GBL is useful in promoting learning outcomes for typically strenuous and difficult subjects. Furthermore, Oyelere et al [82] developed a "MobileEdupuzzle" game for programming education. The game works by making students arranging misarranged lines of code. Over fifty-one students who participated in the study, seventy percent expressed that they were able to effectively learn programming with the experience.

These findings make GBL an ideal tool to motivate and increase participation when it comes to learning how to program. According to Santos et al [83], students appreciate the challenges that come with programming-based games as well as the achievement system to keep them motivated. Furthermore, Taylor et al [84] found that the development of computational thinking skills can also be enhanced by incorporating block-based programming into GBL applications. However, students with prior programming experience have found games with increasing difficulty levels to be tiring. It is therefore important to consider the participants' knowledge of programming when developing a programming-based game. Various approaches discussed in this section are summarised in Table I.

TABLE I. SUMMARY OF GAME-BASED LEARNING APPLICATIONS FOR COMPUTER PROGRAMMING EDUCATION

\begin{tabular}{|l|l|l|}
\hline Author(s) & Methodology & Outcome \\
\hline Mathrani et al [78] & $\begin{array}{l}\text { Programming a robot } \\
\text { with command blocks }\end{array}$ & $\begin{array}{l}\text { Improved learning } \\
\text { effectiveness and } \\
\text { engagement }\end{array}$ \\
\hline $\begin{array}{l}\text { Olsson and } \\
\text { Mozelius [79] }\end{array}$ & $\begin{array}{l}\text { Memory game to teach } \\
\text { data types }\end{array}$ & $\begin{array}{l}\text { Improved learning } \\
\text { effectiveness }\end{array}$ \\
\hline $\begin{array}{l}\text { Wong and Yatim } \\
\text { [80] }\end{array}$ & $\begin{array}{l}\text { Mapping OOP concepts } \\
\text { to in-game activities }\end{array}$ & $\begin{array}{l}\text { Improved learning } \\
\text { effectiveness }\end{array}$ \\
\hline Kalogiannakis [81] & $\begin{array}{l}\text { Programming based quiz } \\
\text { game }\end{array}$ & $\begin{array}{l}\text { Improved learning } \\
\text { effectiveness and } \\
\text { engagement }\end{array}$ \\
\hline Oyelere et al [82] & $\begin{array}{l}\text { Programming based } \\
\text { puzzle game }\end{array}$ & $\begin{array}{l}\text { Improved learning } \\
\text { effectiveness }\end{array}$ \\
\hline
\end{tabular}

\section{F. Virtual Reality for Computer Programming Education}

Alternatively, virtual reality can also be used to make programming classes more immersive and efficient. Pears et al [85] argued that visualisation is necessary to reduce the distance between the programming language and the student's mental models. For example, Vincur et al [86] combined both VR and game elements with block-based programming to introduce basic programming concepts called "Cubely". Cubely consists of cubes that represent programming concepts that can be arranged to form blocks of code. In other words, students must build code from code blocks to control the character to overcome challenges. Results from this study 
showed that over nineteen participants, eighteen preferred using Cubely due to the ease of use over typical code bootcamps available online.

Tanielu et al [87] developed a VR experience called "OOPVR" to reduce the abstractness of OOP concepts with analogies. To help students better understand the relationship between classes and objects, OOPVR uses a blueprint of a house to represent a class where many houses can be built from the same blueprint, signifying that multiple objects can be instantiated from a class. Various analogies were done in a similar manner throughout OOPVR to represent concepts like encapsulation, methods, and instances. To evaluate if the house analogy was effective in visualizing OOP concepts, the authors analysed results from a total of seventeen participants. Compared to the pre-questionnaires, post-questionnaires revealed that the participants showed higher confidence when it comes to visualizing OOP concepts. Bouali et al [88] developed a VR game called "Imikode" to help students familiarise themselves with OOP concepts. The system allows students to create virtual worlds with code. For instance, to instantiate an object, the command "fox = new Fox()" is used, creating a fox in the virtual world. The authors, however, have not yet done tests to determine the effectiveness of the system.

Consequently, Chen et al [89] developed a VR game that allows students to create levels to challenge their peers. Before starting the game, the student playing the role of the level creator will write codes in the virtual environment to place robot characters around the environment that will act as obstacles. Students who then play the game are required to acquire hints scattered around the virtual environment while overcoming the obstacles set up by the previous student. In a sense, students will be able to judge the effectiveness of their own code depending on how the system reacts. The authors claim that students of age nine to thirteen who tried the game have provided positive feedback in terms of engagement and learning effectiveness. Segura et al [90] developed a VR game called "VR-OCKS" that requires students to use code functions represented with blocks in the game to complete puzzles. To test the effectiveness of the system, twenty participants that have played VR-OCKS and another twenty participants who didn't play the game were recruited. Each group of twenty participants was further halved to complete challenges synonymous with the puzzles presented in VR-OCKS in "Kodu" and "Blockly", two popular systems that utilise visual programming to help students learn programming. Results indicated that those who played VR-OCKS before were able to complete twenty-five percent more levels than those who didn't. A summary of the approaches discussed in this section is shown in Table II.

\section{G. Gender and Games}

Throughout the years, many studies have been carried out regarding games and gender. The results of these studies have shown that gender preferences are a key motivator when it comes to playing specific game types [91], [92]. Considering how GBL has proven to be an effective tool for education, gender preference considerations are important in ensuring equal participation. Thus, the purpose of this section is to shed light on factors that appeal to a specific gender when it comes to games, specifically digital games. Lastly, game characteristics that are disliked by females will also be presented in this section.

To determine the preferred game design characteristics of different genders, Spieler and Slany [93] compiled programs developed by participants on the Pocket Code platform using a visual programming environment. In terms of game genre and themes, it is found that both females and males used the adventure genre in their games. However, males prefer the space theme whereas females prefer the nature-based themes. As for game mechanics, both genders used experience points as rewards and challenges in the form of missions in which there is an achievement system. The presence of leaderboards in male-created games is a key difference between the genders. This fact is supported by Hassouneh and Brengman [94] who argued that males value achievement more than females. Consequently, although challenges in games remain the main motivator for both genders, young men are more motivated by games that engage players to reach higher levels as well as beating the game [95]. When it comes to game aesthetics, the narrative, sensation, and fantasy elements are used by both genders but are more apparent in female-created games. The exploration element is, however, exclusive to games created by female pupils, where challenges of the game will lead to the discovery of new parts of the virtual world. This statement also coincides with the argument of Zhou et al [96], where games that include exploration and experimentation elements are generally preferred by female players.

TABLE II. SUMMARY OF VIRTUAL REALITY APPLICATIONS FOR COMPUTER PROGRAMMING EDUCATION

\begin{tabular}{|l|l|l|}
\hline Author(s) & Methodology & Outcome \\
\hline $\begin{array}{l}\text { Vincur et al } \\
{[86]}\end{array}$ & $\begin{array}{l}\text { Code blocks to solve } \\
\text { challenges }\end{array}$ & $\begin{array}{l}\text { Users preferred this approach } \\
\text { over traditional online } \\
\text { bootcamps }\end{array}$ \\
\hline $\begin{array}{l}\text { Tanielu et al } \\
{[87]}\end{array}$ & $\begin{array}{l}\text { Mapping OOP concepts } \\
\text { to in-game activities }\end{array}$ & $\begin{array}{l}\text { Users showed higher confidence } \\
\text { in understanding OOP concepts }\end{array}$ \\
\hline $\begin{array}{l}\text { Bouali et al } \\
{[88]}\end{array}$ & $\begin{array}{l}\text { Forming worlds virtually } \\
\text { with code }\end{array}$ & No findings \\
\hline $\begin{array}{l}\text { Chen et al } \\
{[89]}\end{array}$ & Level creation with code & $\begin{array}{l}\text { Improved learning effectiveness } \\
\text { and engagement }\end{array}$ \\
\hline $\begin{array}{l}\text { Segura et al } \\
{[90]}\end{array}$ & $\begin{array}{l}\text { Solving challenges with } \\
\text { programming blocks }\end{array}$ & Improved learning effectiveness \\
\hline
\end{tabular}

TABLE III. SUMMARY OF FINDINGS REGARDING GENDER AND GAMES

\begin{tabular}{|l|l|}
\hline Author(s) & Findings \\
\hline Spieler and Slany [93] & $\begin{array}{l}\text { Space and nature themes preferred by male and } \\
\text { females correspondingly. }\end{array}$ \\
\hline $\begin{array}{l}\text { Hassouneh and } \\
\text { Brengman [94] }\end{array}$ & Males value achievement more than females. \\
\hline Lucas and Sherry [95] & $\begin{array}{l}\text { Males focuses on reaching higher levels and } \\
\text { beating the game. }\end{array}$ \\
\hline Zhou et al [96] & $\begin{array}{l}\text { Females prefer exploration and } \\
\text { experimentation. }\end{array}$ \\
\hline DeCamp [97] & Violence is preferred by males. \\
\hline Hanh [98] & $\begin{array}{l}\text { Females do not appreciate negative portrayals of } \\
\text { female characters. }\end{array}$ \\
\hline
\end{tabular}


Most games portray female characters as weak individuals who are often rescued by males to attract players. As a result, females do not enjoy or avoid games because they do not appreciate the negative portrayals of female characters [97]. Similarly, violence in games is also one of the main factors contributing to a low number of female gamers. Whereas males are more interested in violence in games, females are less interested in violence [98]. In essence, the low rate of female participation in computer science means that there are more male game developers, who in turn, design and develop games that mainly attract males. This, in turn, lowers the number of female gamers that creates a negative cycle. Table III shows a summary of all the findings from the studies mentioned.

\section{DISCUSSION}

Inaccurate stereotypes that are instilled by society regarding computing have negatively affected females in many ways. Stereotypical depictions of computing foster negative attitudes towards the field, perpetuating the already large gender gap. This issue also affects females who are already in the field where they are often deemed as less capable compared to their male peers. This lowers their confidence levels and sense of belonging which often leads to student dropouts. Ultimately, this is the root of the issue that must be immediately resolved.

Furthermore, it is worth discussing how the use of GBL and virtual reality or combinations of both techniques can help solve issues related to the gender gap in computing (RQ1). In section VI A, it is seen that the utilisation of games in education is capable of increasing student motivation. When lessons are presented in the form of games, students are more willing to participate in lessons. As seen in section VI C, virtual reality enables students to experience unconventional situations that may be inaccessible in real life due to costs and safety reasons. Compared to learning from a textbook, the unconventional presentation of lessons in the virtual environment can also lead to increased participation. It is also important to note that the combination of both GBL and virtual reality techniques may solve some limitations related to one or both approaches. For example, some virtual learning experiences ([76] and [77]) were reported to be non-engaging. Considering that game-based applications are capable of engaging students, this problem can potentially be fixed by employing game elements into the virtual experience. Moreover, both GBL and virtual reality applications specifically developed for computing education have reported outcomes such as increased learners' satisfaction and general improvements to the learning process (Table I and Table II). Seeing how females often lose interest in computing due to boring and abstract lessons, the use of immersive games can be used to simulate how code can be used to solve real-world problems that are more interesting. Immersive games can also foster cooperation with multiplayer modes that are beneficial in increasing the sense of belonging of females in computing. Thus, this makes GBL and virtual reality or the combination of both techniques suitable for increasing female participation in the field of computer science.

Unfortunately, outcomes such as increasing female participation remain scarce in immersive programming gamesbased research. Existing applications highlighted in this review are mainly focused on learning syntax and programming concepts. While existing solutions are effective in retaining those, who are already enrolled in computing-based courses, it does not provide the necessary "appeal" to initiate female interest towards the field. Hence, we require solutions that are specially catered to increasing female participation as it is found that females are more likely to play games that are designed with them in mind [99]. To aid in fostering more research in this area, the "Gender and games" section aims to help future researchers employ game elements that are more appealing to a female audience (RQ2). As seen in Table III, some of the game elements that should be implemented to foster female interests when developing immersive games pertaining to computing education include implementing exploration, experimentation, space, and nature themes. Other than that, the application developed should not feature any violence, negative portrayals of female characters and should not focus too much on achievements.

\section{SUGGESTIONS FOR FUTURE WORK}

There are multiple takeaways from the literature reviewed in this paper. To increase the sense of belonging of females in the field of computing, immersive games developed especially for this purpose should focus on promoting confidence. Since the relationship between confidence and sense of belonging is directly proportional, future work should be done by keeping this fact in mind [100]. This may be done by accessing potential factors that demote confidence and using elements of immersive games to mitigate the issue. For example, [39] observed that females face a dip in confidence when they are unable to immediately observe the results of their work. A potential solution for this is to develop a system that allows users to instantly see the effects of their code writing as seen in Fig. 3. In both game and virtual environments, this can be achievable by changing or slightly altering in-game environments to match user-written code.

To ensure female students do not lose motivation when learning computer programming, retention is important. Hence, it would be worthwhile to develop frameworks that can effectively balance the "fun" and "learning" components of game-based applications. This is important in educational contexts as the system should be able to foster motivation to learn without being too distracting to users. In other words, ingame goals should not overpower learning outcomes. Fig. 4 shows a general flow diagram of how to determine the game elements that motivate but do not distract users to balance the "fun" and "learning" elements mentioned previously. Essentially, researchers should use the flowchart depicted in Fig. 4 to determine, first, if a specific game element incites motivation, then to determine whether that element is also nondistracting before deciding to implement that element in their system. As far as virtual reality is concerned, future works should be aimed at developing experiences for the masses. Regarding software, the use of low-poly graphics should be explored in such a way as to allow accessibility for those with lower-end peripherals. This is necessary to ensure that female students would be able to utilise these tools, regardless of their socio-economic backgrounds. 


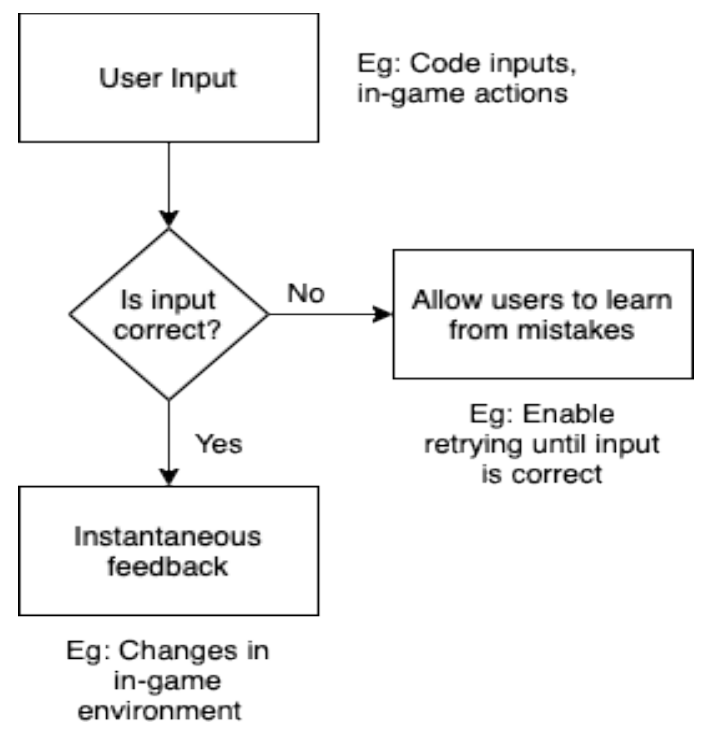

Fig. 3. Flowchart of a System that Allows for Instant Feedback.

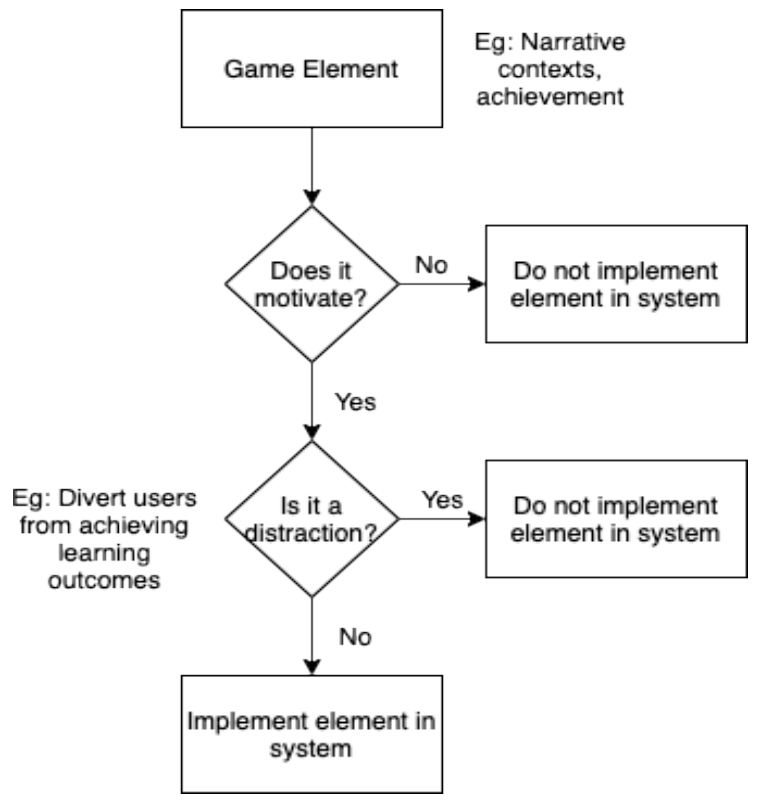

Fig. 4. Decision Flowchart Determines whether Game Elements are Capable of Inciting Motivation without being Distracting.

To aid female students who do not have prior programming knowledge, further research can be done to identify the issues faced by students when learning introductory programming. Specifically, determining why it is difficult for students to understand the concepts of variables, arrays, loops, and if statements. As it stands, most research concerns factors such as lack of intrinsic motivation, perception, and socio-economic backgrounds as a reason for students not to do well in computer programming. Hence, a deeper insight into how students perceive programming concepts without the use of immersive games is necessary to develop appropriate solutions.

Finally, to further increase female participation in the field of computer science, more research should be done to determine how different genders respond to the elements of the game in an educational context. For example, one can continue to determine how males and females react to a high scoreboard in an educational immersive game. Consequently, it is also possible to find out how the high score board impacts the confidence levels in both genders. By doing so, it will be possible to decide whether to include certain elements when developing the system. Specifically, this is useful for developing educational systems for fields of study with large gender gaps, as in the case of females in computing.

\section{CONCLUSION}

This paper provides a review that highlights reasons affecting female participation in computing with a focus on how stereotypical perceptions of computers prevent females from seeking careers in computer science. Additionally, the advantages of GBL, such as the ability to foster intrinsic motivation and knowledge acquisition, are also discussed in detail, along with their disadvantages in educational settings. Existing game-based applications for computer education are also highlighted, looking at how they work and how they compare to each other. This review also sheds some light on existing virtual-game-based applications and how virtual reality is used in education, specifically in the computing field. Lastly, a summary of how males and females respond to different game elements and their preferences is also discussed.

Along with this, discussions and several suggestions have been made regarding further research that can be done. Suggestions include a flow-chart to increase female selfefficacy and sense of belonging to the use of computing immersive games, developing frameworks that balance "fun" and "learning" elements in immersive games, identifying how students struggle with understanding programming concepts and analysing how different genders react to certain game elements. The purpose of this review is to encourage more research in the development of immersive learning applications to reduce gender gaps in computing.

\section{REFERENCES}

[1] W. Farrell, 'The Education of Our Sons: A Look at the Educational State of $2018 . \quad$ hoys', 2 h://whitehouseboysmen.org/wpcontent/uploads/2018/03/The-Education-of-Our-Sons.pdf

[2] 'Women in STEM | Percentages of Women in STEM Statistics', 2019. https://www.stemwomen.co.uk/blog/2019/09/women-in-stempercentages-of-women-in-stem-statistics

[3] I. Isphording and P. Qendrai, 'Gender Differences in Student Dropout in STEM’, IZA Institute of Labor Economics, 2019.

[4] K. Nolan, A. Mooney, and S. Bergin, 'An Investigation of Gender Differences in Computer Science Using Physiological, Psychological and Behavioural Metrics', in Proceedings of the Twenty-First Australasian Computing Education Conference on - ACE '19, Sydney, NSW, Australia, 2019, pp. 47-55. doi: 10.1145/3286960.3286966.

[5] 'AP Program Participation and Performance Data 2019', 2019.

[6] A. Robinson and M. A. Pérez-Quiñones, 'Underrepresented middle school girls: on the path to computer science through paper prototyping', in Proceedings of the 45th ACM technical symposium on Computer science education - SIGCSE '14, Atlanta, Georgia, USA, 2014, pp. 97102. doi: 10.1145/2538862.2538951.

[7] S. Fayer, A. Lacey, and A. Watson, 'STEM Occupations: Past, Present, And Future', U.S. Bureau of Labor Statistics, 2017.

[8] 'NCWIT Scorecard: The Status Of Women In Computing', National Center for Women \& Information Technology, 2018.

[9] M. H. Hussein, S. H. Ow, L. S. Cheong, M.-K. Thong, and N. Ale Ebrahim, 'Effects of Digital Game-Based Learning on Elementary 
Science Learning: A Systematic Review', IEEE Access, vol. 7, pp. 62465-62478, 2019, doi: 10.1109/ACCESS.2019.2916324.

[10] T. Mitamura, Y. Suzuki, and T. Oohori, 'Serious games for learning programming languages', in 2012 IEEE International Conference on Systems, Man, and Cybernetics (SMC), Seoul, Korea (South), Oct. 2012, pp. 1812-1817. doi: 10.1109/ICSMC.2012.6378001.

[11] M. A. Miljanovic and J. S. Bradbury, 'A Review of Serious Games for Programming', in Serious Games, vol. 11243, S. Göbel, A. GarciaAgundez, T. Tregel, M. Ma, J. Baalsrud Hauge, M. Oliveira, T. Marsh, and P. Caserman, Eds. Cham: Springer International Publishing, 2018, pp. 204-216. doi: 10.1007/978-3-030-02762-9_21.

[12] J. P. da Silva and I. F. Silveira, 'A Systematic Review on Open Educational Games for Programming Learning and Teaching', Int. J. Emerg. Technol. Learn., vol. 15, no. 09, p. 156, May 2020, doi: 10.3991/ijet.v15i09.12437.

[13] S. Kavanagh, A. Luxton-Reilly, B. Wuensche, and B. Plimmer, 'A systematic review of Virtual Reality in education', Themes in Science and Technology Education, vol. 10, no. 2, pp. 85-119, 2017.

[14] J. Radianti, T. A. Majchrzak, J. Fromm, and I. Wohlgenannt, 'A systematic review of immersive virtual reality applications for higher education: Design elements, lessons learned, and research agenda', Computers \& Education, vol. 147, p. 103778, Apr. 2020, doi: 10.1016/j.compedu.2019.103778.

[15] N. Johnson, J. Garcia, and K. Seppi, 'Women in CS: Changing the Women or Changing the World?', in 2019 IEEE Frontiers in Education Conference (FIE), Covington, KY, USA, Oct. 2019, pp. 1-8. doi: 10.1109/FIE43999.2019.9028562.

[16] T. C. Peck, L. E. Sockol, and S. M. Hancock, 'Mind the Gap: The Underrepresentation of Female Participants and Authors in Virtual Reality Research', IEEE Trans. Visual. Comput. Graphics, vol. 26, no. 5, pp. 1945-1954, May 2020, doi: 10.1109/TVCG.2020.2973498.

[17] 'Bureau of Labor Statistics Employment Projections', U.S. Bureau of Labor Statistics, $2019 . \quad$ [Online]. Available: https://www.bls.gov/emp/tables/emp-by-detailed-occupation.html

[18] 'Current Term Enrollment Estimates', National Student Clearinghouse Research Center, 2019.

[19] B. Khan, C. Robbins, and A. Okrent, 'The State of U.S. Science and Engineering 2020’, SCIENCE \& ENGINEERING INDICATORS, 2020.

[20] L. Wang, G. Stanovsky, L. Weihs, and O. Etzioni, 'Gender Trends in Computer Science Authorship', Allen Institute for Artificial Intelligence, Seattle, Washington, USA, 2019.

[21] J. Forman et al., 'Automobile injury trends in the contemporary fleet: Belted occupants in frontal collisions', Traffic Injury Prevention, vol. 20, no. 6, pp. 607-612, Aug. 2019, doi: 10.1080/15389588.2019.1630825.

[22] J. Munafo, M. Diedrick, and T. A. Stoffregen, 'The virtual reality headmounted display Oculus Rift induces motion sickness and is sexist in its effects', Exp Brain Res, vol. 235, no. 3, pp. 889-901, Mar. 2017, doi: 10.1007/s00221-016-4846-7.

[23] J. Taylor, M. Harris, and S. Taylor, 'Parents Have Their Say...About Their What a Career Center Can Do For You College-Age Children's Career Decisions', Nace Journal, vol. 64, no. 2, pp. 15-21, 2004.

[24] J. L. Smith, K. L. Lewis, L. Hawthorne, and S. D. Hodges, 'When Trying Hard Isn't Natural: Women's Belonging With and Motivation for MaleDominated STEM Fields As a Function of Effort Expenditure Concerns', Pers Soc Psychol Bull, vol. 39, no. 2, pp. 131-143, Feb. 2013, doi: 10.1177/0146167212468332.

[25] A. J. Hussain, L. Connell, H. Francis, D. Al-Jumeily, P. Fergus, and N. Radi, 'An Investigation into Gender Disparities in the Field of Computing', in 2015 International Conference on Developments of ESystems Engineering (DeSE), Duai, United Arab Emirates, Dec. 2015, pp. 20-25. doi: 10.1109/DeSE.2015.17.

[26] M. N. Giannakos et al., 'Identifying dropout factors in information technology education: A case study', in 2017 IEEE Global Engineering Education Conference (EDUCON), Athens, Greece, Apr. 2017, pp. 1187-1194. doi: 10.1109/EDUCON.2017.7942999.

[27] Z. Hazari, G. Sonnert, P. M. Sadler, and M.-C. Shanahan, 'Connecting high school physics experiences, outcome expectations, physics identity, and physics career choice: A gender study', J. Res. Sci. Teach., p. n/a-n/a, 2010, doi: 10.1002/tea.20363.
[28] D. Baker, 'What Works: Using Curriculum and Pedagogy to Increase Girls' Interest and Participation in Science', Theory Into Practice, vol. 52, no. 1, pp. 14-20, Jan. 2013, doi: 10.1080/07351690.2013.743760.

[29] P. Kuhn and M.-C. Villeval, 'Are Women More Attracted to Cooperation Than Men?', National Bureau of Economic Research, Cambridge, MA, w19277, Aug. 2013. doi: 10.3386/w19277.

[30] W. Khalil, S. Nayab, T. Naeed, S. Khan, and S. Khalil, 'Female representation in computer science and information technology', in 2015 International Conference on Information and Communication Technologies (ICICT), Karachi, Pakistan, Dec. 2015, pp. 1-10. doi: 10.1109/ICICT.2015.7469574.

[31] A. Hoegh and B. M. Moskal, 'Examining science and engineering students' attitudes toward computer science', in 2009 39th IEEE Frontiers in Education Conference, San Antonio, TX, USA, Oct. 2009, pp. 1-6. doi: 10.1109/FIE.2009.5350836.

[32] D. Gürer and T. Camp, 'An ACM-W literature review on women in computing', SIGCSE Bull., vol. 34, no. 2, p. 121, Jun. 2002, doi: $10.1145 / 543812.543844$.

[33] Jo Tondeur, Sarah Van de Velde, Hans Vermeersch, and Mieke Van Houtte, 'Gender Differences in the ICT Profile of University Students: A Quantitative Analysis', DiGeSt. Journal of Diversity and Gender Studies, vol. 3, no. 1, p. 57, 2016, doi: 10.11116/jdivegendstud.3.1.0057.

[34] S. Cheryan, A. N. Meltzoff, and S. Kim, 'Classrooms matter: The design of virtual classrooms influences gender disparities in computer science classes', Computers \& Education, vol. 57, no. 2, pp. 1825-1835, Sep. 2011, doi: 10.1016/j.compedu.2011.02.004.

[35] A. Fisher and J. Margolis, 'Unlocking the clubhouse: the Carnegie Mellon experience', SIGCSE Bull., vol. 34, no. 2, pp. 79-83, Jun. 2002, doi: 10.1145/543812.543836.

[36] C. Frieze and J. L. Quesenberry, 'How computer science at CMU is attracting and retaining women', Commun. ACM, vol. 62, no. 2, pp. 2326, Jan. 2019, doi: 10.1145/3300226.

[37] W. IFIP TC9/WG9.1 International Conference on Women and Computerization, E. Balka, and R. Smith, Women, work, and computerization: charting a course to the future: IFIP TC9 WG9.1 Seventh International Conference on Women, Work, and Computerization, June 8-11, 2000, Vancouver, British Columbia, Canada. 2000. Accessed: Jan. 09, 2020. [Online]. Available: https://doi.org/10.1007/978-0-387-35509-2

[38] M.-P. Chen, 'The Effects of Prior Computer Experience and Gender on High School Students' Learning of Computer Science Concepts from Instructional Simulations', in 2010 10th IEEE International Conference on Advanced Learning Technologies, Sousse, Tunisia, Jul. 2010, pp. 610-612. doi: 10.1109/ICALT.2010.173.

[39] J. J. LaBouliere, A. Pelloth, C.-L. Lu, and J. Ng, 'An exploration of the attitudes of young girls toward the field of computer science', in 2015 IEEE Frontiers in Education Conference (FIE), Camino Real El Paso, El Paso, TX, USA, Oct. 2015, pp. 1-6. doi: 10.1109/FIE.2015.7344265.

[40] W. M. Bramer, M. L. Rethlefsen, J. Kleijnen, and O. H. Franco, 'Optimal database combinations for literature searches in systematic reviews: a prospective exploratory study', Syst Rev, vol. 6, no. 1, p. 245, Dec. 2017, doi: 10.1186/s13643-017-0644-y.

[41] S. Erhel and E. Jamet, 'Digital game-based learning: Impact of instructions and feedback on motivation and learning effectiveness', Computers \& Education, vol. 67, pp. 156-167, Sep. 2013, doi: 10.1016/j.compedu.2013.02.019.

[42] H.-Y. Sung and G.-J. Hwang, 'A collaborative game-based learning approach to improving students' learning performance in science courses', Computers \& Education, vol. 63, pp. 43-51, Apr. 2013, doi: 10.1016/j.compedu.2012.11.019.

[43] M. D. Kickmeier-Rust and D. Albert, 'Micro-adaptivity: protecting immersion in didactically adaptive digital educational games: Microadaptivity in digital educational games', Journal of Computer Assisted Learning, vol. 26, no. 2, pp. 95-105, Mar. 2010, doi: 10.1111/j.13652729.2009.00332.x.

[44] K. H. Li, S.-J. Lou, T.-F. Cheng, and H.-Y. Tsai, 'Application of Gamebased Learning (GBL) on Chinese Language Learning in Elementary School', in 2012 IEEE Fourth International Conference On Digital Game 
And Intelligent Toy Enhanced Learning, Takamatsu, Japan, Mar. 2012, pp. 226-230. doi: 10.1109/DIGITEL.2012.61.

[45] C. H. C. Yan and F. Tam, 'Learning Chinese History through Digital Game', in 2010 Third IEEE International Conference on Digital Game and Intelligent Toy Enhanced Learning, Kaohsiung, Taiwan, Apr. 2010, pp. 156-160. doi: 10.1109/DIGITEL.2010.49.

[46] W. R. Watson, C. J. Mong, and C. A. Harris, 'A case study of the in-class use of a video game for teaching high school history', Computers \& Education, vol. 56, no. 2, pp. 466-474, Feb. 2011, doi: 10.1016/j.compedu.2010.09.007.

[47] M. Ebner and A. Holzinger, 'Successful implementation of user-centered game based learning in higher education: An example from civil engineering', Computers \& Education, vol. 49, no. 3, pp. 873-890, Nov. 2007, doi: 10.1016/j.compedu.2005.11.026.

[48] K. Harris and D. Reid, 'The Influence of Virtual Reality Play on Children'S Motivation', Can J Occup Ther, vol. 72, no. 1, pp. 21-29, Feb. 2005, doi: 10.1177/000841740507200107.

[49] M. Papastergiou, 'Digital Game-Based Learning in high school Computer Science education: Impact on educational effectiveness and student motivation', Computers \& Education, vol. 52, no. 1, pp. 1-12, Jan. 2009, doi: 10.1016/j.compedu.2008.06.004.

[50] R. Silva, R. Rodrigues, and C. Leal, 'Play it again: how game-based learning improves flow in Accounting and Marketing education', Accounting Education, vol. 28, no. 5, pp. 484-507, Sep. 2019, doi: 10.1080/09639284.2019.1647859.

[51] V. Cezar, P. Garcia, V. Botelho, and E. Miletto, 'Towards an RPG Game to Teach Calculus', in 2019 IEEE 19th International Conference on Advanced Learning Technologies (ICALT), Maceió, Brazil, Jul. 2019, pp. 116-118. doi: 10.1109/ICALT.2019.00037.

[52] S.-T. Yong, P. Gates, A. Chan, C.-S. Lee, R. Matthews, and K.-M. Tiong, 'Exploring the Feasibility of Computer Games in Mathematics Education', in 2019 IEEE International Symposium on Haptic, Audio and Visual Environments and Games (HAVE), Subang Jaya, Malaysia, Oct. 2019, pp. 1-6. doi: 10.1109/HAVE.2019.8921018.

[53] J.-J. Lo and F.-M. Lin, 'A Study of 2nd Grade Students' Attitude on a Mathematics Game', in 2012 IEEE Fourth International Conference On Digital Game And Intelligent Toy Enhanced Learning, Takamatsu, Japan, Mar. 2012, pp. 111-113. doi: 10.1109/DIGITEL.2012.29.

[54] N. J. Hogle, W. D. Widmann, A. O. Ude, M. A. Hardy, and D. L. Fowler, 'Does Training Novices to Criteria and Does Rapid Acquisition of Skills on Laparoscopic Simulators Have Predictive Validity or Are We Just Playing Video Games?', Journal of Surgical Education, vol. 65, no. 6, pp. 431-435, Nov. 2008, doi: 10.1016/j.jsurg.2008.05.008.

[55] D. Stefanidis, M. W. Scerbo, C. Sechrist, A. Mostafavi, and B. T. Heniford, 'Do novices display automaticity during simulator training?', The American Journal of Surgery, vol. 195, no. 2, pp. 210-213, Feb. 2008, doi: 10.1016/j.amjsurg.2007.08.055.

[56] C. Green and D. Bavelier, 'Enumeration versus multiple object tracking: the case of action video game players', Cognition, vol. 101, no. 1, pp. 217-245, Aug. 2006, doi: 10.1016/j.cognition.2005.10.004.

[57] J. Feng, I. Spence, and J. Pratt, 'Playing an Action Video Game Reduces Gender Differences in Spatial Cognition', Psychol Sci, vol. 18, no. 10, pp. 850-855, Oct. 2007, doi: 10.1111/j.1467-9280.2007.01990.x.

[58] C. P. Barlett, C. L. Vowels, J. Shanteau, J. Crow, and T. Miller, 'The effect of violent and non-violent computer games on cognitive performance', Computers in Human Behavior, vol. 25, no. 1, pp. 96-102, Jan. 2009, doi: 10.1016/j.chb.2008.07.008.

[59] J. Piaget, Play, dreams, and imitation in childhood. London: Routledge \& K. Paul, 1967. Accessed: May 21, 2021. [Online]. Available: http://books.google.com/books?id=-9F-AAAAMAAJ

[60] M. Kickmeier-Rust, D. Schwarz, D. Albert, D. Verpoorten, J. Castaigne, and M. Bopp, 'The ELEKTRA project: Towards a new learning experience', M3-Interdisciplinary Aspects on Digital Media \& Education, pp. 19-48, 2006.

[61] M. Pohl, M. Rester, and P. Judmaier, 'Interactive Game Based Learning: Advantages and Disadvantages', in Universal Access in HumanComputer Interaction. Applications and Services, vol. 5616, C. Stephanidis, Ed. Berlin, Heidelberg: Springer Berlin Heidelberg, 2009, pp. 92-101. doi: 10.1007/978-3-642-02713-0_10.
[62] D. Gibson, C. Aldrich, and M. Prensky, Eds., Games and Simulations in Online Learning: Research and Development Frameworks. IGI Global, 2007. doi: 10.4018/978-1-59904-304-3.

[63] J. Huizenga, W. Admiraal, and S. Akkerman, 'Learning history by playing a mobile city game', in Proceedings of the 1st European Conference on Game-Based Learning (ECGBL) October 2007, University of Paisley, Paisley, Scotland, 2007, pp. 127-134.

[64] F. M. Dinis, A. S. Guimaraes, B. R. Carvalho, and J. P. P. Martins, 'Virtual and augmented reality game-based applications to civil engineering education', in 2017 IEEE Global Engineering Education Conference (EDUCON), Athens, Greece, Apr. 2017, pp. 1683-1688. doi: 10.1109/EDUCON.2017.7943075.

[65] F. Kharvari and W. Hohl, 'The Role of Serious Gaming using Virtual Reality Applications for 3D Architectural Visualization', in 2019 11th International Conference on Virtual Worlds and Games for Serious Applications (VS-Games), Vienna, Austria, Sep. 2019, pp. 1-2. doi: 10.1109/VS-Games.2019.8864576.

[66] M. Boyles, J. Rogers, K. Goreham, M. A. Frank, and J. Cowan, 'Virtual Simulation for Lighting \&\#x00026; Design Education', in 2009 IEEE Virtual Reality Conference, Lafayette, LA, Mar. 2009, pp. 275-276. doi: 10.1109/VR.2009.4811052.

[67] G. Zhang, 'Virtual Simulation for History Education', in 2019 IEEE Conference on Virtual Reality and 3D User Interfaces (VR), Osaka, Japan, Mar. 2019, pp. 1646-1651. doi: 10.1109/VR.2019.8797734.

[68] J.-L. Lugrin et al., 'A Location-Based VR Museum', in 2018 10th International Conference on Virtual Worlds and Games for Serious Applications (VS-Games), Wurzburg, Sep. 2018, pp. 1-2. doi: 10.1109/VS-Games.2018.8493404.

[69] N. R. Caluya and M. E. C. Santos, 'Kantenbouki VR: A Virtual Reality Authoring Tool for Learning Localized Weather Reporting', in 2019 IEEE Conference on Virtual Reality and 3D User Interfaces (VR), Osaka, Japan, Mar. 2019, pp. 866-867. doi: 10.1109/VR.2019.8798216.

[70] J. H. Seo et al., 'Anatomy builder VR: Applying a constructive learning method in the virtual reality canine skeletal system', in 2017 IEEE Virtual Reality (VR), Los Angeles, CA, USA, 2017, pp. 399-400. doi: 10.1109/VR.2017.7892345.

[71] A. de Mauro, J. Raczkowsky, M. E. Halatsch, and H. Worn, 'Virtual Reality Training Embedded in Neurosurgical Microscope', in 2009 IEEE Virtual Reality Conference, Lafayette, LA, Mar. 2009, pp. 233-234. doi: 10.1109/VR.2009.4811031.

[72] P. Rajeswaran, T. Kesavadas, P. Jani, and P. Kumar, 'AirwayVR: Virtual Reality Trainer for Endotracheal Intubation-Design Considerations and Challenges', in 2019 IEEE Conference on Virtual Reality and 3D User Interfaces (VR), Osaka, Japan, Mar. 2019, pp. 1130-1131. doi: 10.1109/VR.2019.8798249.

[73] J. Dong, J. Zhang, X. Ma, P. Ren, Z. C. Qian, and Y. V. Chen, 'Virtual Reality Training with Passive Haptic Feedback for CryoEM Sample Preparation', in 2019 IEEE Conference on Virtual Reality and 3D User Interfaces (VR), Osaka, Japan, Mar. 2019, pp. 892-893. doi: 10.1109/VR.2019.8797918.

[74] A. S. Mathur, 'Low cost virtual reality for medical training', in 2015 IEEE Virtual Reality (VR), Arles, Camargue, Provence, France, Mar. 2015, pp. 345-346. doi: 10.1109/VR.2015.7223437.

[75] Lei Wei, Hailing Zhou, A. K. Soe, and S. Nahavandi, 'Integrating Kinect and haptics for interactive STEM education in local and distributed environments', in 2013 IEEE/ASME International Conference on Advanced Intelligent Mechatronics, Wollongong, NSW, Jul. 2013, pp. 1058-1065. doi: 10.1109/AIM.2013.6584234.

[76] I. Y. T. Hsiao, I. Y. S. Li, Y. J. Lan, J. J. S. Huang, and S. J. H. Ynag, 'Development of a virtual campus on Second Life: A case study of NCU wonderland', in Workshop Proceedings of the 18th International Conference on Computers in Education, Putrajaya, Malaysia, 2010, pp. 241-247.

[77] P. H. Hsieh, Y. H. Wu, and F. M. Ma, 'A study of visitor's learning needs and visit satisfaction in real and Second Life museums', in Workshop Proceedings of the 18th International Conference on Computers in Education, ICCE 2010, Putrajaya, Malaysia, 2010, pp. 248-255. 
[78] A. Mathrani, S. Christian, and A. Ponder-Sutton, 'PlayIT: Game Based Learning Approach for Teaching Programming Concepts', Educational Technology \& Society, vol. 19, no. 2, pp. 5-17, 2016.

[79] M. Olsson and P. Mozelius, 'Learning to Program by Building Learning Games', in Proceedings of the the 11th European Conference on GameBased Learning ECGBL 2017, 2017, pp. 448-454.

[80] Y. S. Wong and M. H. M. Yatim, 'A Propriety Multiplatform GameBased Learning Game to Learn Object-Oriented Programming', in 2018 7th International Congress on Advanced Applied Informatics (IIAI-AAI), Yonago, Japan, Jul. 2018, pp. 278-283. doi: 10.1109/IIAIAAI.2018.00060.

[81] S. Papadakis and M. Kalogiannakis, 'Evaluating the effectiveness of a game-based learning approach in modifying students' behavioural outcomes and competence, in an introductory programming course. A case study in Greece', IJTCS, vol. 10, no. 3, p. 235, 2019, doi: 10.1504/IJTCS.2019.102760.

[82] S. S. Oyelere, F. J. Agbo, I. T. Sanusi, A. A. Yunusa, and K. Sunday, 'Impact of Puzzle-Based Learning Technique for Programming Education in Nigeria Context', in 2019 IEEE 19th International Conference on Advanced Learning Technologies (ICALT), Maceió, Brazil, Jul. 2019, pp. 239-241. doi: 10.1109/ICALT.2019.00072.

[83] A. L. dos Santos, M. R. de A. Souza, M. Dayrell, and E. Figueiredo, 'Exploring Game Elements in Learning Programming: An Empirical Evaluation', in 2018 IEEE Frontiers in Education Conference (FIE), San Jose, CA, USA, Oct. 2018, pp. 1-9. doi: 10.1109/FIE.2018.8658505.

[84] S. Taylor et al., 'Position: IntelliBlox: A Toolkit for Integrating BlockBased Programming into Game-Based Learning Environments', in 2019 IEEE Blocks and Beyond Workshop (B\&B), Memphis, TN, USA, Oct. 2019, pp. 55-58. doi: 10.1109/BB48857.2019.8941222.

[85] A. Pears et al., 'A survey of literature on the teaching of introductory programming', SIGCSE Bull., vol. 39, no. 4, p. 204, Dec. 2007, doi: 10.1145/1345375.1345441.

[86] J. Vincur, M. Konopka, J. Tvarozek, M. Hoang, and P. Navrat, 'Cubely: virtual reality block-based programming environment', Association for Computing Machinery, pp. 1-2, 2017.

[87] T. Tanielu, R. 'Akau'ola, E. Varoy, and N. Giacaman, 'Combining Analogies and Virtual Reality for Active and Visual Object-Oriented Programming', in Proceedings of the ACM Conference on Global Computing Education - CompEd '19, Chengdu,Sichuan, China, 2019, pp. 92-98. doi: 10.1145/3300115.3309513.

[88] N. Bouali, E. Nygren, S. S. Oyelere, J. Suhonen, and V. Cavalli-Sforza, 'Imikode: A VR Game to Introduce OOP Concepts', in Proceedings of the 19th Koli Calling International Conference on Computing Education Research - Koli Calling '19, Koli, Finland, 2019, pp. 1-2. doi: $10.1145 / 3364510.3366149$.
[89] J. Chen, M. R. Zargham, M. Rajendren, and J. Cheng, 'Coding VR Games', in Int'l Conf. Frontiers in Education: CS and CE, 2019, pp. 123127.

[90] R. J. Segura, F. J. Pino, C. J. Ogáyar, and A. J. Rueda, 'VR-OCKS: A virtual reality game for learning the basic concepts of programming', Comput Appl Eng Educ, vol. 28, no. 1, pp. 31-41, Jan. 2020, doi: 10.1002/cae.22172.

[91] L. Vermeulen and J. Van Looy, “'I Play So I Am?” A Gender Study into Stereotype Perception and Genre Choice of Digital Game Players', Journal of Broadcasting \& Electronic Media, vol. 60, no. 2, pp. 286-304, Apr. 2016, doi: 10.1080/08838151.2016.1164169.

[92] B. Manero, J. Torrente, C. Fernandez-Vara, and B. Fernandez-Manjon, 'Investigating the Impact of Gaming Habits, Gender, and Age on the Effectiveness of an Educational Video Game: An Exploratory Study', IEEE Trans. Learning Technol., vol. 10, no. 2, pp. 236-246, Apr. 2017, doi: 10.1109/TLT.2016.2572702.

[93] B. Spieler and W. Slany, 'Game Development-Based Learning Experience: Gender Differ- ences in Game Design’, Sophia Antipolis, France, 2018, pp. 616-625.

[94] D. Hassouneh and M. Brengman, 'A motivation-based typology of social virtual world users', Computers in Human Behavior, vol. 33, pp. 330338, Apr. 2014, doi: 10.1016/j.chb.2013.08.012.

[95] K. Lucas and J. L. Sherry, 'Sex Differences in Video Game Play:: A Communication-Based Explanation', Communication Research, vol. 31, no. 5, pp. 499-523, Oct. 2004, doi: 10.1177/0093650204267930.

[96] Z. Zhou, X.-L. Jin, D. R. Vogel, Y. Fang, and X. Chen, 'Individual motivations and demographic differences in social virtual world uses: An exploratory investigation in Second Life', International Journal of Information Management, vol. 31, no. 3, pp. 261-271, Jun. 2011, doi: 10.1016/j.ijinfomgt.2010.07.007.

[97] S. Hahn, 'Researching the Gender Divide of Digital Games: How to Overcome the Virtuous Cycle of the Games Industry', Acta Ludica, vol. 2, pp. 6-24, 2018.

[98] W. DeCamp, 'Who plays violent video games? An exploratory analysis of predictors of playing violent games', Personality and Individual Differences, vol. 117, pp. 260-266, Oct. 2017, doi: 10.1016/j.paid.2017.06.027.

[99] C. Stewart-Gardiner, G. Carmichael, J. Latham, N. Lozano, and J. Greene, 'Influencing middle school girls to study computer science through educational computer games', Journal of Computing Sciences in Colleges, vol. 28, no. 6, pp. 90-97, 2013.

[100]A. Nguyen and C. M. Lewis, 'Competitive Enrollment Policies in Computing Departments Negatively Predict First-Year Students' Sense of Belonging, Self-Efficacy, and Perception of Department', in Proceedings of the 51st ACM Technical Symposium on Computer Science Education, Portland OR USA, Feb. 2020, pp. 685-691. doi: $10.1145 / 3328778.3366805$. 